\title{
Exploration of the Application of MOOC to College Education
}

\author{
Ma Yujie \\ School of Foreign Languages, Jiangsu University of Technology Changzhou, Jiangsu Province, China \\ myj0621@jsut.edu.cn
}

\begin{abstract}
MOOC (Massive Open Online Courses), an online course aimed at large-scale participation and open access via the Internet, has aroused growing attention of academic circles both at home and abroad. In western countries, MOOC has been applied to teaching and proven effective to some extent. The paper discusses the feasibility of applying MOOC to college education and analyzes its drawbacks. Based on that, the author proposes the possible ways to overcome these drawbacks, i.e. teacher's optimization of digital resources and control of student learning process, hoping to contribute to today's college education.
\end{abstract}

Index Terms - MOOC, online teaching, college education

\section{Introduction}

Globalization and information has brought a dramatic rise of new educational forms, i.e. internetwork, social media, etc, which led to the birth of new learning patterns and frameworks, such as OER (Open Educational Resource), etc. Against the background, MOOC was first proposed by George Seimens and Steven Downes in Manitoba University, Canada. According to Downes, the emergence of MOOC would transform the teaching mode from a traditional and teachercentered one to a distributed and student-centered one [1].

The reform of college education has long been the concern of China's educational world. Online teaching platform and web-based teaching mode have been brought to it. MOOC, which has been applied to teaching in western countries and proven effective, is superior to general webbased teaching modes in following aspects: (1) a mass of fine academic resources; (2) free access to resources for global learners; (3) open-ended learning content and result. This paper attempts to explore the possibility and efficiency of applying MOOC to China's college education.

\section{Feasibility of Applying MOOC to College Education}

In college, each student may vary from the other in terms of learning interest, capacity and method, which calls for various teaching methods and resources. With a huge amount of resources offered by MOOC, almost every specific demand of every individual learner can be met, and experts or educators of a specific field may be lucky enough to arouse the interest of some students [2]. Therefore, college teachers do not have to take sole responsibility of fulfilling each student's needs because MOOC caters to students of different levels. Hopefully, a win-win result between teachers and learners can be obtained.

\section{Drawbacks of MOOC}

A. Randomness in learning

MOOC is regarded as one of the most successful modes that can well motivate learners for it endows learners with the freedom to choose whatever learning materials they like. However, it is meanwhile criticized for its randomness in learning. One of the reasons might be that college students who are supposed to be young and weak-minded tend to learn something out of curiosity or temperate interest and quit whenever they find it is boring or difficult. Without any guide or restriction, students can hardly improve their learning result systematically.

\section{B. Low completion rate}

Statistics show that around $10 \%$ of the people who sign up MOOCs complete the course [3]. For example, one of the first MOOCs in 2008 had 2200 registered members, of whom 150 actively interacted at various times [4]. Early data from Coursera (MOOCs founded by computer science professors Andrew $\mathrm{Ng}$ and Daphne Koller from Stanford University) suggest a completion rate of 7\%-9\% [5].

Phil Hill classifies people signed up MOOCs into 5 types (Fig. 1) [6]:

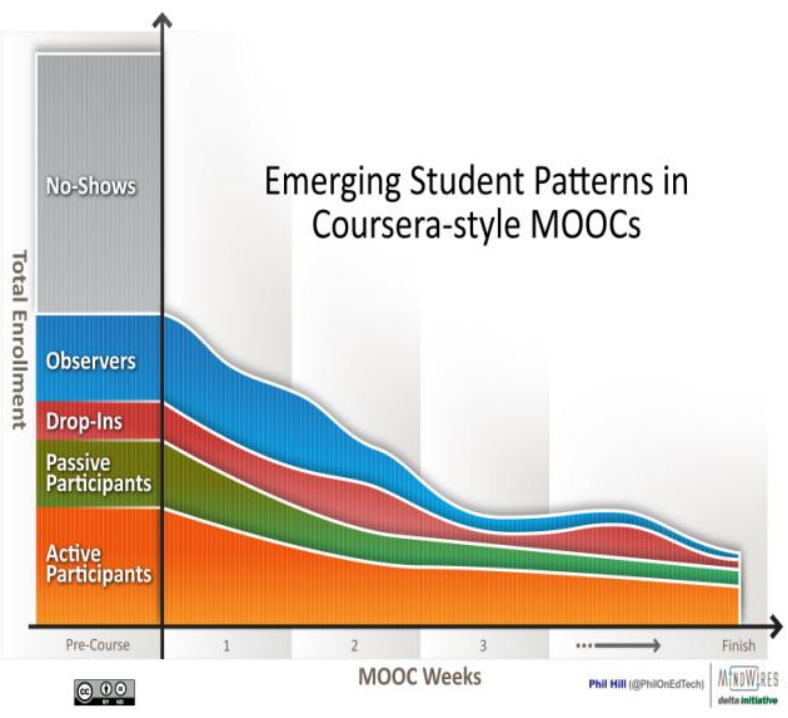

Fig. 1: Emerging Student Patterns in Coursera-style MOOCs

As shown in Fig. 1, five types of learners are as follows:

- No-Shows: the largest group of those registering, who register but never login to the course while it is active. 
- Observers: those who login and may read content or browse discussions occasionally but do not take any form of assessment.

- Drop-Ins: those who might watch videos or participate in discussion forum but do not attempt to complete the entire course.

- Passive Participants: students who view a course as content to consume, but generally do not engage with the assignments.

- Active Participants: students who fully intend to participate in the MOOC and take part in discussion forums, the majority of assignments and all quizzes and assessments.

Based on previous data and figure, it is obvious that selfdiscipline of learners plays a key role in MOOC. Learners would easily get lost in numerous resources and drop out due to reasons such as lack of time [7].

\section{Absence of an Effective Assessment Mechanism}

Online assessments are very different from the traditional version. The two most common methods of MOOC assessment are machine-graded multiple-choice quizzes or tests and peer- reviewed written assignments [8]. Great effort has been devoted to proctoring and cheating. There is still a long way off the wide recognition of the authority and rigor of MOOC assessment.

\section{Exploration and Reflections}

No teaching method is perfect and MOOC is not free from drawbacks either. However, if teachers and students play their due roles, MOOC can be well applied to and boost college education.

\section{A. Optimization of Digital Teaching Resources}

College students might simply feel confused when faced with enormous online learning resources. Under the circumstances, teachers are supposed to play the role of a learning assistant, offering help and guiding students when necessary to help them hunt for useful information and carry out a continuous and systematic learning process.

Besides, an even more important task for teachers is to screen useful online information and to optimize digital teaching resources for students (Fig 2):

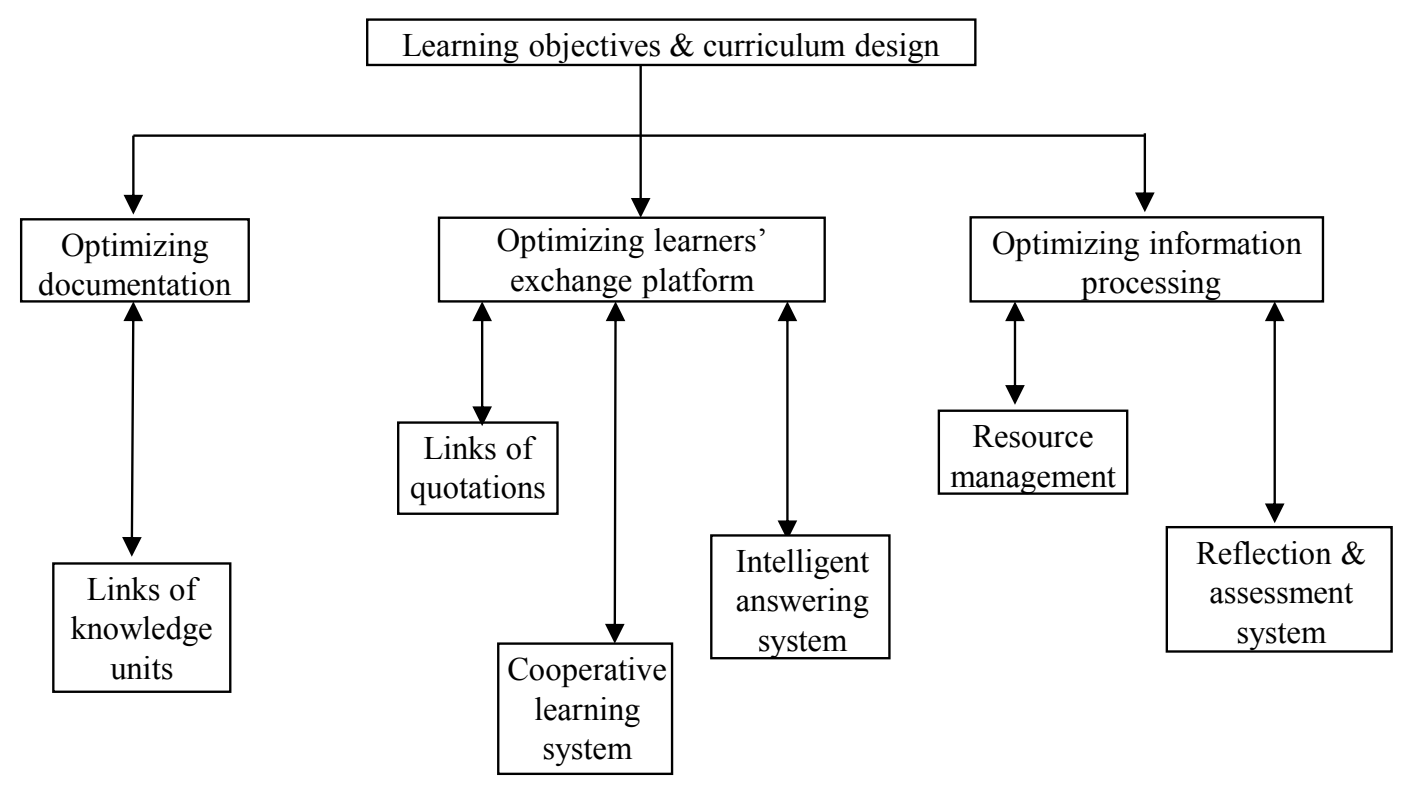

Fig. 2: Optimization of digital teaching resources.

According to Fig. 2, optimized digital learning resources can be attained in the following ways:

- Curriculum should be carefully designed based on learning objective;

- Digital learning process can be optimized in terms of documentation, learners' exchange platform and information process;

- Make full use of MOOC resources and network information to optimize documentation; take advantage of network channel to optimize exchange platforms; establish an immediate feedback and assessment mechanism to inform learners learning outcomes.
It is noteworthy that MOOCs or any other online resources are a cognitive tool and affective motivation rather than a sheer learning object or assistant, whose ultimate purpose is to give full play to learners' initiative and enthusiasm.
B. Taking Effective Control of Student Learning Process
To cope with MOOC's low completion rate, following suggestions might be helpful:
- Dividing video lectures into several micro ones, with questions and answers, quizzes or interactive communication as intervals, so as to keep learners focused. 
- Flipped classroom. By flipped classroom, we mean that students are supposed to preview each MOOC video lecture before a face-to-face discussion with other learners and teachers. Compared with traditional teaching mode, MOOC is inferior in terms of social experience, interpersonal relationship, emotional contact between teachers and students, etc. Flipped classroom can hopefully resolve this problem.

- Building an exchange platform. It is encouraged to invite professors and teachers of all schools and experts of various circles to be on-line instructors; joint exchange platform with other schools is also welcome.

\section{Discussions}

MOOC, a breakthrough to traditional education, has broadened the horizon of both teachers and students and boosted the advancement of higher education. The benefits brought about by the application of MOOC to college education are obvious: free access to abundant high-quality online resources; freedom to learn the content of interest; immunity from the restriction of time and space of a certain course.

Still, there are a few limitations for MOOC if it is to be applied to college education: random in learning, low completion rate, to name a few. While applying MOOC to college education, teachers are highly important, who are supposed to optimize digital resources and guide students along with their learning process. However, like other online courses, MOOC has also been challenged as to its accuracy and objectiveness of assessment mechanism. Till now, there is no easy resolution to this perplexity. To obtain an accurate assessment of a student performance, it calls for great endeavor, and effective cooperation between teachers and students is also indispensable.

\section{Acknowledgment}

This work was supported by Foundation of Jiangsu University of Technology (JG13012).

\section{References}

[1] S. Downes, "Connectivism \& Connective Knowledge," [EB/OL]. http://ltc.umanitoba.ca/connectivism/?p=59.

[2] A. McAuley, B. Stewart, G. Siemens, and D. Cormier, "The MOOC Model for Digital Practice," Proc. Knowledge Synthesis Grants on the Digital Economy, 2010, pp.6-10.

[3] D. Catropa, (24 February 2013). "Big (MOOC) Data," [EB/OL] http://www.nytimes.com/2013/02/21/education/universities-abroad-joinmooc-course-projects.html.

[4] J. Mackness, S. Mak and R. Williams, "The Ideals and Reality of Participating in a MOOC," Proc. 7th International Conference on Networked Learning, 2010, pp.266-275.

[5] D. Koller, "MOOCs on the Move: How Coursera Is Disrupting the Traditional Classroom (text and video)," Knowledge @ Wharton Podcast. University of Pennsylvania. 7 November 2012. Retrieved 23 April 2013.

[6] P. Hill, (March 10, 2013). "Emerging Student Patterns in MOOCs: A (Revised) Graphical View," [EB/OL] http://mfeldstein.com/emergingstudent-patterns-in-moocs-a-revised-graphical-view/.

[7] A. Fini, "The Technological Dimension of a Massive Open Online Course: The Case of the CCK08 Course Tools," The International Review of Research in Open and Distance Learning, vol.10, no. 5, 2009.

[8] "Degree of Freedom - an adventure in online learning," MOOC Components - Assessment, (22 March 2013) [EB/OL] http://degreeoffreedom.org/mooc-components-assessment/ 